\title{
Análise da abordagem interdisciplinar e contextualizada na área de ciências naturais em livros didáticos do $9^{\circ}$ ano
}

Analysis of the interdisciplinary and contextualized approach in natural sciences in $9^{\text {th }}$ year school books

Análisis del enfoque interdisciplinario y contextualizado en el área de ciencias naturales en libros de texto de $9^{\circ}$ grado

\section{Resumo}

O livro didático tem como principal função orientar, auxiliar e servir de ferramenta de apoio para o professor. Diante disso, esta pesquisa objetivou analisar a presença da interdisciplinaridade e a contextualização, nas atividades experimentais e exercícios, presentes em livros didáticos da área de Ciências Naturais para o Ensino Fundamental. Foi delimitado como foco o objeto de conhecimento "aspectos quantitativos das transformações químicas" proposto para o nono ano na unidade temática "matéria e energia", de acordo com a Base Nacional Comum Curricular. Para a análise da interdisciplinaridade e da contextualização, considerou-se todos os exercícios propostos nos capítulos que abrangem o objeto de conhecimento. Para a investigação da contextualização, foram adotadas as categorias de avaliação espacial, numérica, temporal, cultural e/ou social. Das 123 questões analisadas, 87\% apresentaram interdisciplinaridade e contextualização. Quanto à contextualização, 65\% das questões avaliadas denotam dados numéricos, $25 \%$ retratam o espaço, $16 \%$ datas e épocas (temporal) e $4 \%$ a contextualização (social/cultural). A combinação "numérica e espacial" obteve destaque em associar mais de um tipo de contextualização. Somente um (1) livro didático incentivou atividades por meio de projetos e $80 \%$ das atividades totais incentivaram a produção de trabalhos em grupos. Foram utilizados na maioria das questões não verbais, textos com figuras; mapas conceituais, esquemas e outros tipos de metodologias de aprendizagem não foram utilizadas nas atividades experimentais e exercícios, apenas como resumo de conteúdos finais de capítulos. Por fim, ampliar o conceito da interdisciplinaridade no Ensino de Ciências para áreas distintas é notório, visto que, na análise desta pesquisa, nenhum exercício dos livros didáticos retratou a História da Ciência, explorando datas, nomes e o contexto em que ocorre a produção científica. Palavras-chave: Contextualização; Ensino de ciências; Experimentação; Interdisciplinaridade; Matéria e energia.

\begin{abstract}
The textbook's main function is to guide, assist and serve as a support tool for the teacher. Therefore, this research aimed to analyze the presence of interdisciplinarity and contextualization, in experimental activities and exercises, present in textbooks in Natural Sciences for Elementary School. The focus was defined as the object of knowledge "quantitative aspects of chemical transformations" proposed for the ninth year in the thematic unit "matter and energy", according to the Common National Curriculum Base. For the analysis of interdisciplinarity and contextualization, all the exercises proposed in the chapters that cover the object of knowledge were considered. For the investigation of contextualization, the categories of spatial, numerical, temporal, cultural and/or social assessment were adopted. Of the 123 questions analyzed, 87\% presented interdisciplinarity and contextualization. As for contextualization, $65 \%$ of the questions evaluated denote numerical data, $25 \%$ portray the space, $16 \%$ dates and times (temporal) and $4 \%$ contextualization (social/cultural). The "numerical and spatial" combination was highlighted in associating more than one type of contextualization. Only one (1) textbook encouraged activities through projects and $80 \%$ of the total activities encouraged the production of work in groups. Texts with pictures were used in most nonverbal questions; Concept maps, schematics and other types of learning methodologies were not used in the
\end{abstract}


experimental activities and exercises, only as a summary of the final contents of the chapters. Finally, extending the concept of interdisciplinarity in Science Teaching to different areas is notorious, since, in the analysis of this research, no textbook exercise portrayed the History of Science, exploring dates, names and the context in which scientific production occurs.

Keywords: Contextualization; Science teaching; Experimentation; Interdisciplinarity; Matter and energy.

\section{Resumen}

La función principal del libro de texto es guiar, asistir y servir como herramienta de apoyo para el maestro. Por tanto, esta investigación tuvo como objetivo analizar la presencia de la interdisciplinariedad y contextualización, en actividades y ejercicios experimentales, presentes en los libros de texto del área de Ciencias Naturales para la Educación Primaria. El enfoque se definió como el objeto de conocimiento "aspectos cuantitativos de las transformaciones químicas" propuesto por noveno año en la unidad temática "materia y energía", según la Base Curricular Nacional Común. Para el análisis de la interdisciplinariedad y contextualización se consideraron todos los ejercicios propuestos en los capítulos que abordan el objeto de conocimiento. Para la investigación de la contextualización se adoptaron las categorías de valoración espacial, numérica, temporal, cultural y / o social. De las 123 preguntas analizadas, el $87 \%$ presentó interdisciplinariedad y contextualización. En cuanto a la contextualización, el $65 \%$ de las preguntas evaluadas denotan datos numéricos, el 25\% retratan el espacio, el 16\% fechas y horas (temporal) y el $4 \%$ contextualización (social / cultural). Se destacó la combinación "numérica y espacial" al asociar más de un tipo de contextualización. Solo un (1) libro de texto fomentaba las actividades a través de proyectos y el $80 \%$ del total de actividades fomentaba la producción de trabajo en grupo. Se utilizaron textos con imágenes en la mayoría de las preguntas no verbales; Los mapas conceptuales, esquemas y otro tipo de metodologías de aprendizaje no se utilizaron en las actividades y ejercicios experimentales, solo como resumen de los contenidos finales de los capítulos. Finalmente, es notorio extender el concepto de interdisciplinariedad en la Enseñanza de las Ciencias a diferentes áreas, ya que, en el análisis de esta investigación, ningún ejercicio de libro de texto retrató la Historia de la Ciencia, explorando fechas, nombres y el contexto en el que se da la producción científica.

Palabras clave: Contextualización; Enseñanza de las ciencias; Experimentación; Interdisciplinariedad; Materia y energía.

\section{Introdução}

A busca contínua por um Ensino de Ciências (EC) que aproxima teoria e prática envolvendo Atividades Experimentais (AE) e exercícios de forma lúdica, se tornou notória no campo de pesquisa da Educação. Para Novak (1981), Pozo e Crespo (2009) e, Catelan e Rinaldi (2018) o professor deve aplicar a sua ação didática baseada em um ensino significativo e que busca aperfeiçoar a relação entre professor e aluno. Para os autores a aprendizagem não ocorre sem envolvimento de ações concretas, é preciso haver interação, criticidade e criatividade, tão essenciais quando se pensa no EC.

Em 1996, o Ministério da Educação (MEC) publicou a Lei de Diretrizes e Bases da Educação Nacional (LDBEN) com o propósito de oferecer novos rumos para a Educação Básica (Brasil, 1996). Posteriormente, surgiram diversos documentos governamentais como os Parâmetros Curriculares Nacionais (PCN) em 1997, as Diretrizes Curriculares Nacionais (DCN) em 2013, o Plano Nacional de Educação (PNE) em 2014 e a Base Nacional Comum Curricular (BNCC) em 2017 com a finalidade de promover uma Educação de qualidade aos estudantes brasileiros. Em decorrência da busca pela melhoria no EC, aspectos como a interdisciplinaridade e contextualização foram valorizados.

Daí a necessidade de se estimularem novas formas de organização dos componentes curriculares dispondo-os em eixos temáticos, que são considerados eixos fundantes, pois conferem relevância ao currículo. Desse modo, no projeto político-pedagógico, a comunidade educacional deve engendrar o entrelaçamento entre trabalho, ciência, tecnologia, cultura e arte, por meio de atividades próprias às características da etapa de desenvolvimento humano do escolar a que se destinarem, prevendo: [...] a organização dos tempos e dos espaços com ações efetivas de interdisciplinaridade e contextualização dos conhecimentos (Brasil, 2013, p.50).

Lago et al. (2015) definem a interdisciplinaridade como a necessidade de integrar, articular e trabalhar em conjunto. Segundo Morin e Diaz (2016, p. 32) “a consciência da complexidade leva a uma tomada de consciência da indispensável mudança de paradigma nas ciências, partindo de uma visão simplificadora, unidimensional e parcial, para um conhecimento multidimensional, integrado e complexo". Desse modo, a interdisciplinaridade relacionada à realidade concreta, histórica e 
cultural, requer trabalhar temas no EC de forma contextualizada, em que os alunos construam atitudes e habilidades como participação, autonomia e responsabilidade no processo de ensino aprendizagem (Cardoso et al., 2017).

Neste contexto, o objetivo do presente estudo é analisar a presença da interdisciplinaridade e da contextualização nas AE e exercícios presentes em livros didáticos (LD) da área de Ciências da Natureza (CN) do nono ano do Ensino Fundamental (EF), para a unidade temática "matéria e energia"; objeto de conhecimento "aspectos quantitativos das transformações químicas", de acordo com a BNCC (Brasil, 2017). Assim, acredita-se que AE e exercícios quando elaborados de forma planejada didaticamente, mesmo os que constam no LD, pelo professor podem estimular a motivação e o interesse em aprender.

O professor precisa ter em mente que toda ação didática deve proporcionar o aprendizado significativo e, em relação ao EC é o professor que tem como tornar o aluno "crítico com ideias que podem intervir na sociedade em relação ao meio ambiente, na área tecnológica, na área de Ciências no geral" (Camillo, 2021, p. 8). O artigo está organizado inicialmente pela revisão de aspectos sobre os Livros Didáticos e o PNLD; e Alfabetização Científica: as práticas experimentais e exercícios nos LD. Por sequência, são descritos os procedimentos metodológicos da pesquisa; os resultados e discussões e, para finalizar, as considerações finais.

\subsection{Uma breve reflexão sobre os livros didáticos e o plano nacional do livro didático}

A ampla distribuição de LD na Educação Básica tornou-se efetiva no Brasil pela distribuição do MEC com o Plano Nacional do Livro Didático (PNLD). Todavia, "a trajetória das políticas voltadas para a avaliação, regulação e distribuição dos livros didáticos no Brasil foi marcada por três momentos específicos da história nacional" (Matos, 2012, p.51). O primeiro momento foi marcado pela criação de uma Comissão de Instituição Pública no século XIX, responsável pela elaboração de um projeto de lei para melhorar a organização escolar; o segundo momento propiciou a criação de três comissões durante o século XX: a Comissão Nacional do Livro Infantil (1936), a Comissão Nacional do Ensino Primário (1938) e a Comissão Nacional do Livro Didático (1938); e, por fim, o terceiro momento, com a criação, em 1985, do PNLD (Brasil, 2017).

O PNLD de 2012 foi direcionado à "aquisição e à distribuição integral de livros aos alunos do Ensino Médio, bem como à reposição e complementação do PNLD 2011 ( $6^{\circ}$ ao $9^{\circ}$ ano do ensino fundamental) e do PNLD $2010\left(1^{\circ}\right.$ ao $5^{\circ}$ ano do ensino fundamental)" (Brasil, 2017, n.p.). Esse plano permitiu a distribuição gratuita das obras didáticas, além de subsidiar as ações pedagógicas dos professores.

As obras didáticas são avaliadas e se aprovadas, suas resenhas são publicadas no Guia do LD. Os livros são encaminhados às instituições de ensino para que os professores escolham qual obra atende melhor o projeto político pedagógico da escola para serem utilizados em triênio (Brasil, 2017). Para a escolha do LD de CN em conformidade com a BNCC, é necessário que ele seja aprovado perante critérios eliminatórios e apresente componentes curriculares da Ciência (Brasil, 2013, p.9-10):

1. propostas de atividades que estimulem a investigação científica, por meio da observação, experimentação, interpretação, análise, discussões dos resultados, síntese, registros, comunicação e de outros procedimentos característicos da Ciência;

2. temas de estudo, atividades, linguagem e terminologia científica adequados ao estágio de desenvolvimento cognitivo dos estudantes;

3. iniciação às diferentes áreas do conhecimento científico, assegurando a abordagem de aspectos centrais em física, astronomia, química, geociências, ecologia, biologia e saúde;

4. articulação dos conteúdos de Ciências com outros campos disciplinares;

5. a produção do conhecimento científico como atividade que envolve diferentes pessoas e instituições;

6. a história da ciência muito além de nomes ou datas, explorando o contexto em que ocorreu a produção científica; 
7. textos e atividades que colaborem com o debate sobre as repercussões, relações e aplicações do conhecimento científico na sociedade;

8. orientação para o desenvolvimento de atividades experimentais factíveis, com resultados confiáveis e interpretação teórica correta;

9. incentivo a uma postura de respeito ao ambiente, conservação e manejo corretos;

10. orientações claras e precisas sobre os riscos na realização dos experimentos e atividades propostos visando garantir a integridade física de alunos, professores e demais pessoas envolvidas no processo educacional;

11. propostas de atividades que estimulem a interação e participação da comunidade escolar, das famílias e da população em geral;

12. propostas de visitas a espaços que favoreçam o desenvolvimento do processo de ensino e aprendizagem (museus, centros de ciências, parques zoobotânicos, universidades, centros de pesquisa e outros);

13. propostas de uso de tecnologias da informação e comunicação;

14. orientações para utilizar textos, vídeos, objetos de aprendizagens e outros recursos disponíveis na rede internet, em especial aqueles disponíveis nos Portais do MEC e da Capes;

15. propostas pedagógicas lúdicas para o ensino de ciências.

Os critérios de escolha dos LD estão baseados na participação do aluno em atividades individuais ou em grupos, incluindo alunos com diferentes níveis cognitivos. Inclusive com propostas de atividades que contextualizam o local onde o aluno está inserido, com ações pedagógicas de investigação, sugerindo a experimentação, entre outras. Notou-se que os itens 3 , 4 e 5 orientam que a interdisciplinaridade esteja presente nos $\mathrm{LD}$, bem como, a contextualização em vários critérios que intensificam a sua importância.

\subsection{Alfabetização científica: práticas experimentais e exercícios nos livros didáticos}

A discussão sobre Alfabetização Científica (AC) ganhou notoriedade em meados de 1990, quando houve a necessidade de reformulações no EC, visto que a Ciência impacta diretamente a sociedade, a economia e a vida dos indivíduos. No Brasil, ocorreram vários debates e divergências em torno da nomenclatura que foi traduzida do inglês "Scientific Literacy" para o português, o qual recebeu as traduções de Iniciação Científica, Letramento Científico e Enculturação (Aragão, 2019).

Roberts (2007) argumenta que existem duas visões sobre a definição de AC. Segundo o autor, a Visão I é definida como a compreensão dos conceitos e processos científicos, ou seja, do conhecimento científico puro; já a Visão II enfatiza o caráter social da Ciência, em que o aluno precisa estar apto a resolver certas situações no seu dia a dia, utilizando os conhecimentos científicos.

Em concordância com Aragão (2014), considera-se que um indivíduo alfabetizado cientificamente é hábil para compreender conceitos, princípios e teorias da Ciência, bem como utilizar os conhecimentos científicos para entender o mundo que o cerca, em seus mais diversos contextos. A escola é uma das principais precursoras da AC, com a missão de preparar o sujeito para a vida em sociedade, facilitando-a.

Para Rodrigues e Vestena (2013) a escola deve apresentar e proporcionar ao aluno contato com os conhecimentos recorrentes, mediar e ensinar a enxergar a realidade de forma ampla. Nesta perspectiva, para que o aluno se encontre alfabetizado cientificamente é necessário que o professor estabeleça ações pedagógicas, como experimentações, atividades de investigação e exercícios diversos (em ambiente especializado como em laboratórios ou em sala de aula), sempre buscando adaptar a ação para a realidade do aluno e inclusive para a realidade da escola.

As AE são amplamente abordadas no PNLD, indicando que estas devem aparecer em vários capítulos dos LD de forma adequada, com textos, comentários e ilustrações. Porém, todas as AE devem ser bem planejadas, considerando as realidades distintas das escolas públicas do Brasil, uma vez que, o professor se torna responsável em administrar os desafios que podem surgir. A experimentação tem papel fundamental no EC, sendo necessário que o professor relacione os conceitos teóricos com a ação da $\mathrm{AE}$, oportunizando a compreensão e o real sentido da Ciência.

Santos (2007) afirma que um dos critérios adotados pelos professores para a seleção do LD é a quantidade de 
exercícios, conteúdos, linguagem simples e apropriada, contextualização e as atividades experimentais. Entretanto, em relação à importância de fazer exercícios em sala de aula ou em casa com a finalidade de capacitar o aluno, existem poucas pesquisas relacionadas a esse tema.

Romano (2008) defende que a resolução de exercícios é uma oportunidade do aluno desenvolver a autonomia, aprender, refletir e principalmente, ampliar o seu conhecimento a respeito do que está sendo estudado. Para o autor, existem crenças a respeito dos exercícios e que precisam ser repensadas, como a de que o exercício não ensina, apenas é algo mecânico e repetitivo e, a crença em que a obrigatoriedade do aluno ter que realizar exercícios diários gera, por si só, a responsabilidade e o hábito de estudo.

É preciso que a escola, os professores e a família participem desse processo, para que as AE e os exercícios tenham sucesso na ação pedagógica. É preciso deixar claro para os alunos a relevância desses materiais, para que percebam a sua importância, tenham entusiasmo, motivação e interesse para realizá-los, de forma que faça sentido o aprendizado.

\section{Metodologia}

Este estudo é de cunho qualitativo e documental e, em conformidade com Minayo (2010), é uma pesquisa que proporciona uma construção ou revisão de abordagens, conceitos ou categorias. Busca-se analisar a interdisciplinaridade e a contextualização em AE e exercícios presentes em cinco LD da área de CN do triênio (2017, 2018 e 2019), referente ao nono ano do EF. A unidade temática escolhida foi "matéria e energia" e o objeto de conhecimento "aspectos quantitativos das transformações químicas", conforme dados da BNCC (Brasil, 2017, p.345). Torna-se importante salientar que as obras não precisavam estar alinhadas a BNCC, pois eram obras anteriores a mesma, apenas serviu como referência para a pesquisa.

A unidade temática Matéria e Energia contempla "o estudo de materiais e suas transformações, fontes e tipos de energia utilizados na vida em geral, na perspectiva de construir conhecimento sobre a natureza da matéria e os diferentes usos da energia" (Brasil, 2017, p.345). Diante disso, a BNCC busca que o estudante explore fenômenos relacionados à Matéria e Energia, fazendo uso de AE, para que seja capaz de analisar, refletir e desenvolver ações em prol da sociedade e do meio ambiente ao qual está inserido (Brasil, 2017).

A unidade temática analisada contempla sete habilidades, entre as quais foi selecionada a (EF09CI04) que tem por intuito "Planejar e executar experimentos que evidenciam que todas as cores de luz podem ser formadas pela composição das três cores primárias da luz e que a cor de um objeto está relacionada também à cor da luz que o ilumina" (Brasil, 2017, p.351). A seguir, as respectivas habilidades dispostas na BNCC para a unidade temática "Matéria e Energia" (Figura 1). 
Figura 1. Unidade Temática escolhida para a análise.

\section{HABIUIDADES}

(EFO9C101) Investigar as mudanças de estado fisico da matéria e explicar essas transformaçōes com base no modelo de constituiçăo submicroscópica.

(EFO9C102) Comparar quantidades de reagentes e produtos envolvidos em transformaçōes quimicas, estabelecendo a proporçăo entre as suas massas.

(EFO9CIO3) Identificar modelos que descrevem a estrutura da matéria (constituição do àtomo e composiçăo de moléculas simples) e reconhecer sua evoluçăo histórica.

(EF09C104) Planejar e executar experimentos que evidenciem que todas as cores de luz podem ser formadas pela composição das trés cores primàrias da luz e que a cor de um objeto está relacionada também à cor da luz que o ilumina.

(EFO9CIO5) investigar os principais mecanismos envolvidos na transmissāo e recepçăo de imagem e som que revolucionaram os sistemas de comunicaçăo humana.

(EFO9C106) Classificar as radiaçōes eletromagnéticas por suas frequências, fontes e aplicaçōes, discutindo e avaliando as implicaçōes de seu uso em controle remoto, telefone celular, raio X, forno de micro-ondas, fotocélulas etc.

(EFO9CiO7) Discutir o papel do avanço tecnológico na aplicação das radiaçōes na medicina diagnóstica (raio $X$, ultrassom, ressonáncia nuclear magnética) e no tratamento de doenças (radioterapia, cirurgia ótica a laser, infravermelho, ultravioleta etc.).

Fonte: Base Nacional Comum Curricular (2017, p.351).

Todos os livros selecionados foram requisitados e escolhidos para compor o PNLD, sendo a escolha tida por conveniência, já que os materiais estavam disponíveis em uma escola pública aleatória. No Quadro 1, apresenta-se os dados referentes a cada LD, os quais: autor e o ano; nome do LD; editora e os capítulos analisados que integram o objeto de conhecimento.

Quadro 1. Livros didáticos selecionados.

\begin{tabular}{|l|c|c|c|c|}
\hline LD & Autor/ano & Livro & Editora & Capítulos analisados \\
\hline I & Canto, E. L. (2012) & $\begin{array}{c}\text { Ciências Naturais: Aprendendo com o } \\
\text { cotidiano }\end{array}$ & Coderna & Capítulo 13 e 14 \\
\hline II & Gewandsznajder, F. (2015) & Ciências: matéria e energia & Ática - Projeto Teláris & Capítulo 14 \\
\hline III & Passos, E., \& Sillos, A. (2015) & Tempo de Ciência & Editora Brasil & Tema 4: Capítulo 3 e 4 \\
\hline IV & Trivellato Júnior, J. et al. (2015) & Ciências & Quinteto & Unidade 9: Capítulo 1 e 2 \\
\hline V & Usberco, J.et al. (2015) & Companhia das Ciências & Saraiva & Capítulo 22 e 23 \\
\hline
\end{tabular}

Fonte: Autoras.

Para a análise, primeiramente, buscou-se a presença da ocorrência da interdisciplinaridade nas AE e exercícios, em relação à habilidade previamente escolhida. No que se refere à contextualização (Figura 2), considerou-se a conjuntura que as AE ou exercícios estão relacionados, em conformidade com a unidade temática e com o objeto de conhecimento selecionado (disposto na BNCC); seguindo as categorias criadas por Nicoletti e Sepel (2016): temporal, espacial, cultural, social e/ou numérico. 
Figura 2. Esquema de análise da interdisciplinaridade e contextualização nas atividades experimentais e exercícios.

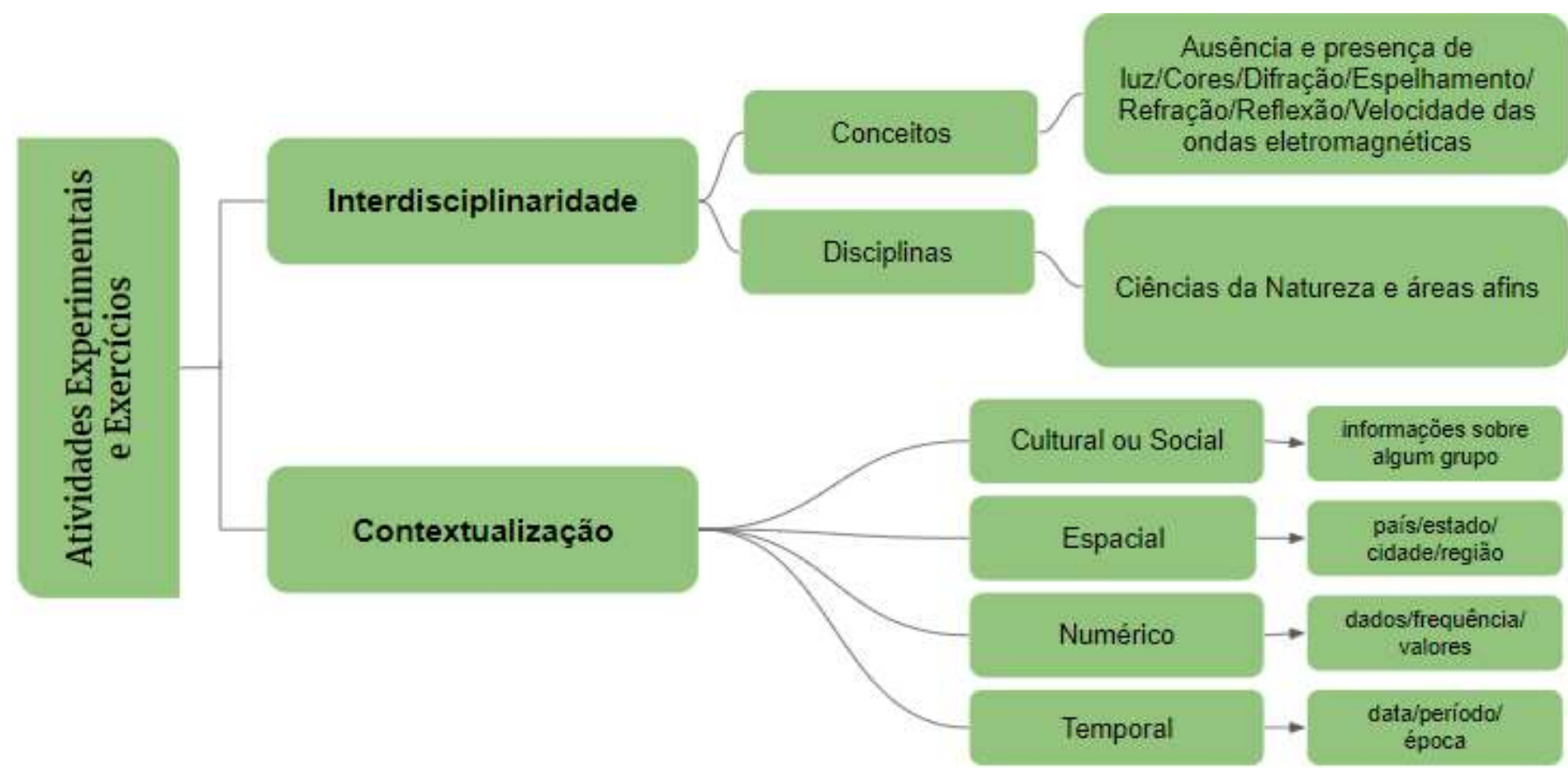

Fonte: Autoras.

Além disso, foi analisado o tipo de gênero discursivo nas questões presentes nos LD. Para isso, foi selecionado aleatoriamente alguns gêneros discursivos com linguagem verbal e não verbal, como mapas conceituais, esquemas, tabelas e figuras. Para Andrade (2016) o LD é muitas vezes o único recurso que o aluno possui como meio de estudo e que proporciona interpretações e compreensão de atividades, valorizando o uso de gêneros discursivos em situações de contextualização. Segundo o PNLD, a linguagem verbal e não verbal são critérios presentes na escolha dos LD e que precisam estar nos componentes curriculares de CN (Brasil, 2013).

Elementos não textuais (tabelas, quadros, gráficos, figuras, mapas e imagens) devem ser inseridos no lugar apropriado do texto, não sendo necessário enviá-los em separado. Eles devem ser colocados após sua citação no texto, tão próximo quanto possível, mas de forma que o elemento gráfico e sua legenda fiquem na mesma página. Veja o exemplo do Quadro1.

\section{Resultados e Discussão}

\subsection{Análise dos termos nos documentos oficiais do Ministério da Educação e Cultura}

A fim de fazer o levantamento sobre a presença da interdisciplinaridade e da contextualização em LD, com base no que rege a $\mathrm{BNCC}$ na área de $\mathrm{CN}$ correspondente ao último ano do EF, realizou-se primeiramente uma busca sobre os termos nos documentos oficiais do MEC que serviram de marcos legais para a elaboração da BNCC, considerando a LDBEN, as DCN e o PNE.

A segunda edição da LDBEN, atualizada em 2017 no Art. 35-A, deixa clara a importância da diversidade dos currículos de $\mathrm{CN}$, os quais devem estar em harmonia com a BNCC, articulando a interdisciplinaridade e o cotidiano em que o aluno está inserido (Brasil, 2017). Nas DCN do ano de 2013, os conceitos de interdisciplinaridade e contextualização ficam tangíveis, uma vez que, é necessário atender as diferenças culturais das diversas regiões e comunidades existentes no Brasil (Brasil, 2013). As DCN também salientam a necessidade de evidenciar a interdisciplinaridade por meio de novas práticas de ensino, como projetos que resgatem a realidade do aluno e que propiciem a aprendizagem elementar (Brasil, 2013). 
O PNE, por sua vez, incentiva a interdisciplinaridade por meio de ações pedagógicas que unifiquem a teoria e a prática, de forma diversificada, flexível e que seja intensificada e articulada com o EC; bem como com as tecnologias, as linguagens e a cultura, a fim de garantir que a educação esteja relacionada com o cotidiano do aluno, vinculando nesta perspectiva a contextualização (Brasil, 2014). Recentemente, o termo contextualização denota estar ausente, principalmente ao analisar a BNCC, porém ele pode ser substituído por 'cotidiano' e 'multicultural'.

Ao pesquisar os termos na plataforma do Google Acadêmico, no período de 2000 a 2020, verificou-se que o termo multicultural apareceu 13.900 vezes; contextualização 69.700 vezes; e cotidiano 466.000 vezes. O termo 'cotidiano' está em ascensão, uma vez que a BNCC é um documento mais recente, do ano de 2017, em comparação às DCN que são de 2013. Em consonância, as pesquisas em torno do termo que estão contidas no Google Acadêmico, também estão ganhando maior notoriedade.

\subsection{Atividades experimentais e exercícios nos livros didáticos: há uma abordagem interdisciplinar e contextualizada?}

Foram avaliadas um total de 123 questões, as quais contemplam AE e exercícios da área de CN nos LD de nono ano do $\mathrm{EF}$, sendo que $87 \%$ são interdisciplinares e contextualizadas. Em relação aos gêneros discursivos utilizados nas $\mathrm{AE}$ e exercícios, compilou-se o número de propostas de questões por capítulos dos LD, bem como a utilização de questões com textos de linguagem verbal (LV) e/ou não verbal (LNV) por capítulo; total dos tipos de questões com textos de LV e LNV por $\mathrm{LD}$; e a porcentagem dos totais gerais de todos os LD, conforme Quadro 2.

Quadro 2. Tipo de linguagem utilizada nas atividades experimentais e exercícios nos livros didáticos selecionados.

\begin{tabular}{|c|c|c|c|c|c|}
\hline LD & $\begin{array}{l}\text { Capítulos } \\
\text { analisados }\end{array}$ & $\begin{array}{c}\text { Número } \\
\text { de } \\
\text { Propostas }\end{array}$ & $\begin{array}{c}\text { Questões com textos de linguagem verbal e/ou não } \\
\text { verbal }\end{array}$ & $\begin{array}{l}\text { Totais por } \\
\text { LD }\end{array}$ & Total geral (\%) \\
\hline \multirow{2}{*}{ I } & Capítulo 13 & 10 & $\begin{array}{c}\text { LV (7) } \\
\text { LV e LNV (3) }\end{array}$ & \multirow{2}{*}{$\begin{array}{l}\text { LV (14) } \\
\text { LV e LNV } \\
\quad(15)\end{array}$} & \multirow{9}{*}{$\begin{array}{l}\text { LV }(57 \%) \\
\text { LV e LNV } \\
\quad(43 \%)\end{array}$} \\
\hline & Capítulo 14 & 19 & $\begin{array}{c}\text { LV (7) } \\
\text { LV e LNV (12) }\end{array}$ & & \\
\hline II & Capítulo 14 & 19 & $\begin{array}{c}\text { LV (7) } \\
\text { LV e LNV (12) }\end{array}$ & $\begin{array}{l}\text { LV (7) } \\
\text { LV e LNV } \\
\quad(12)\end{array}$ & \\
\hline \multirow[t]{2}{*}{ III } & Capítulo 3 & 9 & $\begin{array}{c}\text { LV (7) } \\
\text { LV e LNV (2) } \\
\end{array}$ & \multirow{2}{*}{$\begin{array}{c}\text { LV (18) } \\
\text { LV e LNV (6) }\end{array}$} & \\
\hline & Capítulo 4 & 15 & $\begin{array}{c}\text { LV (11) } \\
\text { LV e LNV (4) }\end{array}$ & & \\
\hline \multirow[t]{2}{*}{ IV } & Capítulo 1 & 16 & $\begin{array}{c}\text { LV (10) } \\
\text { LV e LNV (6) }\end{array}$ & \multirow{2}{*}{$\begin{array}{l}\text { LV (16) } \\
\text { LV e LNV } \\
\quad(13)\end{array}$} & \\
\hline & Capítulo 2 & 13 & $\begin{array}{c}\text { LV (6) } \\
\text { LV e LNV (7) }\end{array}$ & & \\
\hline \multirow[t]{2}{*}{$\mathbf{V}$} & Capítulo 22 & 11 & $\begin{array}{c}\text { LV (8) } \\
\text { LV e LNV (3) }\end{array}$ & \multirow{2}{*}{$\begin{array}{c}\operatorname{LV}(15) \\
\operatorname{LV} \text { e LNV (7) }\end{array}$} & \\
\hline & Capítulo 23 & 11 & $\begin{array}{c}\text { LV (7) } \\
\text { LV e LNV (4) }\end{array}$ & & \\
\hline
\end{tabular}

Fonte: Autoras.

Ao analisar o LD I, verificou-se que das 29 questões gerais, 14 apresentaram questões com textos que utilizam linguagem verbal nos seus enunciados e 15 com linguagem verbal e não verbal; no LD II, das 19 questões propostas, 7 apresentaram textos com linguagem verbal e 12 textos com linguagem verbal e não verbal; no LD III, das 24 questões, 18 apresentaram textos com linguagem verbal e 6 textos com linguagem verbal e não verbal; no LD IV, das 29 questões, 16 apresentaram textos com linguagem verbal e 13 textos com linguagem verbal e não verbal ; no LD V, das 22 questões, 15 apresentaram textos com linguagem verbal e 7 textos com linguagem verbal e não verbal. No total geral, $57 \%$ das questões 
propostas nos cinco LD apresentaram somente textos com linguagem verbal nos seus enunciados e $43 \%$ continham textos com linguagem verbal e não verbal (na sua maioria figuras, com presença de apenas uma tabela).

Uma das competências específicas segundo a BNCC (2017) é a utilização de diferentes gêneros discursivos por meio da linguagem verbal e não verbal. Na maioria das questões não verbais analisadas, se verificou textos com figuras. Mapas conceituais, esquemas e outros tipos de metodologias de aprendizagem não foram utilizadas nas AE e exercícios, porém, em dois LD os mapas conceituais aparecem ao final do capítulo como forma de resumir os principais conteúdos e conceitos abordados.

Embora 57\% das questões propostas apresentem somente textos com linguagem verbal nos seus enunciados, estas estão em conformidade com a BNCC, que se baseou nas DCN, em relação a contextualização e a interdisciplinaridade. Em relação à contextualização, $65 \%$ das questões denotam dados numéricos como: frequências de uma determinada reação química relacionadas a peso, tamanho, distância, velocidade e medida de ângulo; $25 \%$ retratam o espaço que são relativos a planetas, regiões e cidades; $16 \%$ em relação a datas e épocas (temporal) e $4 \%$ a contextualização (social/cultural). A combinação "numérica e espacial" foi a que mais se destacou nas questões que associam mais de um tipo de contextualização. Como exemplos de questões são as que fornecem dados sobre a frequência que uma determinada luz percorre em um determinado espaço de tempo, relacionada a categoria espaço, como o planeta Terra.

Para Novak (1981) e Chassot (2011) se faz necessário que as ações didáticas estejam organizadas em questões sociais para que se direcione à uma aprendizagem científica significante, devendo o professor considerar a vivência cotidiana do aluno, seus saberes, seus valores, interesses e atitudes. Os alunos do nono ano do EF tem uma peculiaridade diferenciada dos demais, pois são sujeitos que estão na adolescência, fase compreendida em uma faixa etária que geralmente vai dos 13 aos 16 anos. Essa fase é evidenciada pelas vivências múltiplas de informações a todo e qualquer momento, o que exige que a escola e o professor modifiquem suas práticas constantemente.

Desta forma, é importante ressaltar o papel que o professor precisa desempenhar, esforçando-se para desafiar o aluno por meio de experimentações e exercícios que o auxiliem a chegar a formulações de hipóteses, criticidade, criatividade e expressar-se cientificamente. Para Santos (2017) o desafio que o professor encontra na contemporaneidade em preparar um jovem como cidadão, em um momento de mudanças na sociedade, leva o professor a exercer um novo papel, porém, condizente com os princípios do ensino e da aprendizagem amparados nas legislações vigentes. Este aluno precisa, segundo Santos (2017, p. 5) "adquirir habilidades como fazer consultas em livros, entender o que lê, tomar notas, fazer síntese, redigir conclusões, interpretar gráficos e dados, realizar experiências e discutir os resultados obtidos e, ainda, usar instrumentos de medida quando necessário, bem como compreender as relações que existem entre os problemas atuais e o desenvolvimento científico.

Em conformidade com Novak (1981), Chassot (2011), Cursino (2017) e Santos (2017), isso ocorrerá a partir do momento em que o professor assumir o papel de mediador do processo de ensino e aprendizagem, com uma postura professorreflexivo e investigativo. O professor "irá colaborar para a construção da autonomia de pensamento e de ação, ampliando a possibilidade de participação social e desenvolvimento mental, capacitando os alunos a exercerem o seu papel de cidadão do mundo" (Santos, 2017, p.05).

Como já foi pontuado, segundo as DCN é necessário que o material didático (no caso os LD) desenvolvam por meio das AE e exercícios a contextualização com base na realidade do aluno e no seu cotidiano. Para tal, enumerou-se alguns exemplos de contextualização retratadas em algumas AE e/ou exercícios presentes nos LD selecionados, conforme o Quadro 3. 
Quadro 3. Atividades contextualizadas nos livros didáticos.

\begin{tabular}{|l|l|}
\hline LD & \multicolumn{1}{|c|}{ Contextualização } \\
\hline I & $\begin{array}{l}\text {-A importância da luz na natureza, nas plantas onde o aluno habita; } \\
\text { - Relaciona o espelhamento com objetos que o aluno lida no seu dia a dia; como os espelhos encontrados nas lojas, } \\
\text { postes, saída de garagens, retrovisor do carro. }\end{array}$ \\
\hline II & $\begin{array}{l}\text { - Utiliza objetos que os alunos conhecem como o rádio, televisão; } \\
\text { - Relaciona os fenômenos da natureza. }\end{array}$ \\
\hline III & $\begin{array}{l}\text { - Utilização de filmes populares para relacionar com a física; } \\
\text { - Relaciona o espelhamento com objetos que o aluno lida no seu dia a dia. }\end{array}$ \\
\hline IV & $\begin{array}{l}\text { - Cores são utilizadas para sinalizar, nas praias como a bandeira vermelha informando do perigo, ou se o mar está } \\
\text { liberado para banho e, os semáforos; } \\
\text { - Utilização de filmes populares e desenhos para relacionar com a física; } \\
\text { - Relaciona o espelhamento com objetos que o aluno lida no seu dia a dia. }\end{array}$ \\
\hline V & $\begin{array}{l}\text { - Enumera objetos do dia a dia dos alunos como a Bandeira do Brasil e as cores; } \\
\text { - Utiliza o ambiente que os alunos estão presentes para fazer experimento de refração e espelhamento. }\end{array}$ \\
\hline
\end{tabular}

Fonte: Autores.

Apenas um (1) LD incentivou atividades por meio de projetos, a realização de uma intervenção com a comunidade local e escolar; bem como, $80 \%$ das atividades totais incentivaram a produção de trabalhos em grupos. A instrução para a escola e para o professor trabalhar com projetos voltados à comunidade, é uma indicação da BNCC, das DCN e do PNLD. Segundo Oliveira (2018) os projetos escolares são ferramentas que auxiliam o professor a colocar em prática a teoria, estimulando o aluno a discutir, a criar e, principalmente, a envolver o aluno em questões que englobam a sociedade. Borges e Alencar (2014) defendem que os projetos escolares são importantes recursos para a formação crítica e reflexiva do aluno, objetivando estimular tomadas de decisões individuais e coletivas.

Com a finalidade de analisar se ocorre a interdisciplinaridade entre duas ou mais disciplinas, buscou-se, por meio do Quadro 4, compilar as principais informações sobre quantas AE estão dispostas nos LD; quantidade de exercícios; se as Tecnologias Digitais de Informação e Comunicação (TDIC) estão presente nos LD; os conceitos que abarcam "Matéria e Energia”, disciplinas em questão e, se são propostas atividades em grupos. 
Quadro 4. Análise das atividades experimentais e dos exercícios propostos nos livros didáticos.

\begin{tabular}{|c|c|c|c|c|c|c|}
\hline LD & $\mathbf{A E}$ & Exercícios & TDIC & Conceitos & Interdisciplinaridade & $\begin{array}{c}\text { Atividades em } \\
\text { Grupo }\end{array}$ \\
\hline \multirow{4}{*}{$\mathbf{I}$} & \multirow{4}{*}{$17 \%$} & \multirow{4}{*}{$83 \%$} & \multirow{4}{*}{ Nada consta } & Cores & Física/Química/Biologia/ & \multirow{4}{*}{3 propostas } \\
\hline & & & & Espelhamento & $\begin{array}{c}\text { Matemática/Física/ } \\
\text { Química/ }\end{array}$ & \\
\hline & & & & Reflexão & Física/Química & \\
\hline & & & & Refração & $\begin{array}{l}\text { Física/Matemática/Artes/ } \\
\text { Português }\end{array}$ & \\
\hline \multirow[t]{4}{*}{ II } & \multirow[t]{4}{*}{$47 \%$} & \multirow[t]{4}{*}{$53 \%$} & \multirow[t]{4}{*}{$\begin{array}{l}\text { Produção de } \\
\text { Vídeos }\end{array}$} & Cores & $\begin{array}{c}\text { Química/Física/ } \\
\text { Matemática }\end{array}$ & \multirow{4}{*}{9 propostas } \\
\hline & & & & Espelhamento & $\begin{array}{c}\text { Matemática/Física/ } \\
\text { Química/ } \\
\text { Literatura/Português }\end{array}$ & \\
\hline & & & & Refração & $\begin{array}{c}\text { Matemática/Geografia/ } \\
\text { Física/História/Geografia }\end{array}$ & \\
\hline & & & & $\begin{array}{l}\text { Velocidade das ondas } \\
\text { eletromagnéticas }\end{array}$ & Biologia/Física/Química & \\
\hline \multirow{5}{*}{ III } & \multirow{5}{*}{$4 \%$} & \multirow{5}{*}{$96 \%$} & \multirow{5}{*}{ Nada consta } & Ausência e Presença de luz & Química & \multirow{5}{*}{1 proposta } \\
\hline & & & & & & \\
\hline & & & & Espelhamento & Física/Matemática & \\
\hline & & & & Refração & $\begin{array}{c}\text { Física/Matemática/ } \\
\text { Biologia }\end{array}$ & \\
\hline & & & & $\begin{array}{c}\text { Velocidade das ondas } \\
\text { eletromagnéticas }\end{array}$ & $\begin{array}{c}\text { Física/Matemática/ } \\
\text { Geografia }\end{array}$ & \\
\hline \multirow{5}{*}{ IV } & \multirow{5}{*}{$14 \%$} & \multirow{5}{*}{$86 \%$} & \multirow{5}{*}{$\begin{array}{l}\text { Produçãa de } \\
\text { Vídeos/ } \\
\text { Cinema/ } \\
\text { hiperlink }\end{array}$} & Absorção da luz & Física & \multirow{5}{*}{3 propostas } \\
\hline & & & & Cores & $\begin{array}{l}\text { Geografia/Química/Física/ } \\
\text { Artes/Português/História }\end{array}$ & \\
\hline & & & & Espelhamento & $\begin{array}{c}\text { Física/Química/Biologia/ } \\
\text { Matemática/Artes/ } \\
\text { Literatura/ } \\
\text { Geografia/Português }\end{array}$ & \\
\hline & & & & Refração & $\begin{array}{c}\text { Biologia/Física/ } \\
\text { Matemática/ } \\
\text { Geografia } \\
\end{array}$ & \\
\hline & & & & Reflexão & Física/Matemática & \\
\hline \multirow{4}{*}{$\mathbf{V}$} & \multirow{4}{*}{$9 \%$} & \multirow{4}{*}{$91 \%$} & \multirow{4}{*}{ Nada consta } & Cores & Física/Química & \multirow{4}{*}{ Nada consta } \\
\hline & & & & Espelhamento & Física/Matemática & \\
\hline & & & & Refração & $\begin{array}{c}\text { Física/Matemática/ } \\
\text { Química }\end{array}$ & \\
\hline & & & & $\begin{array}{c}\text { Velocidade das ondas } \\
\text { eletromagnéticas }\end{array}$ & $\begin{array}{l}\text { Física/Matemática/ } \\
\text { Geografia/História }\end{array}$ & \\
\hline
\end{tabular}

Fonte: Autores.

Ao analisar o Quadro 4, foi averiguado que em todos os LD existem propostas tanto de AE como de exercícios envolvendo o objeto de estudo, com uma média de $18 \%$ de AE e $82 \%$ de exercícios. Conforme as DCN, as AE e os exercícios necessitam estar presentes nos componentes curriculares de $\mathrm{CN}$, pois estes estimulam a investigação científica, despertam a postura do aluno frente ao meio ambiente e incentivam para a interação com a sociedade (Brasil, 2013).

A utilização de vídeos, hiperlinks, objetos de aprendizagens e outros recursos da internet tem se destacado no planejamento atual docente, diante dos avanços nos campos da Ciência e Tecnologia (Brasil, 2013). Contudo, apenas 20\% dos LD trazem esses recursos nos exercícios e AE analisadas, os quais devem incorporar mecanismos das TDIC. Camillo \& Muller (2020) acreditam que o uso adequado das TDIC possibilita uma aprendizagem relevante, desde que com um planejamento adequado.

A difração foi um conceito não contemplado nas AE e exercícios. Todavia, as cores e a refração foram os conceitos 
mais abordados nos experimentos (Figura 3) e, a refração e o espelhamento nos exercícios.

Figura 3. Imagem de uma atividade experimental do livro didático II.

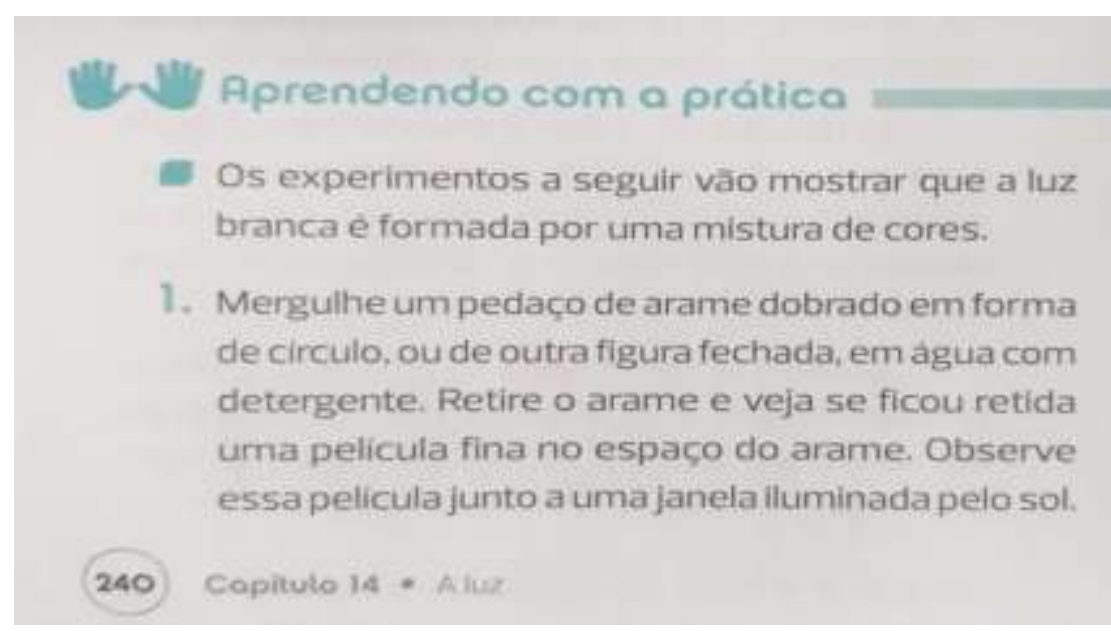

Fonte: Ciência Matéria e Energia (2015, p. 240).

No experimento da Figura 3, a interdisciplinaridade é introduzida mediante a temática de mistura de cores por meio da disciplina de Química e a Matemática se faz presente ao referir-se a figura geométrica plana, círculo ou outra figura qualquer, desde que fechada. A interdisciplinaridade está assídua na grande maioria das AE e dos exercícios dos LD, combinados entre Física, Química, Matemática e Biologia, além de disciplinas como Artes, Geografia, História, Literatura e Português. Também há a presença da articulação com temas transversais da área do conhecimento da Saúde, relacionadas à visão, doenças acometidas, causas e consequências. Contudo, essas análises não estão claras no LD, sendo necessário que o professor analise a interdisciplinaridade presente na atividade e traga para a sala de aula esses apontamentos.

Em algumas AE do LD V, conforme a Figura 4, identificou-se a interdisciplinaridade e a contextualização entre as disciplinas da Física e da Matemática. A Física está contemplada por ser uma AE que visa a propagação retilínea da luz e a Matemática pela indicação da construção de figuras geométricas; em que a contextualização ocorre pela AE ao apresentar dados numéricos e busca com que o aluno utilize materiais comuns do seu cotidiano. 
Figura 4. Imagem de uma atividade experimental do livro didático V.

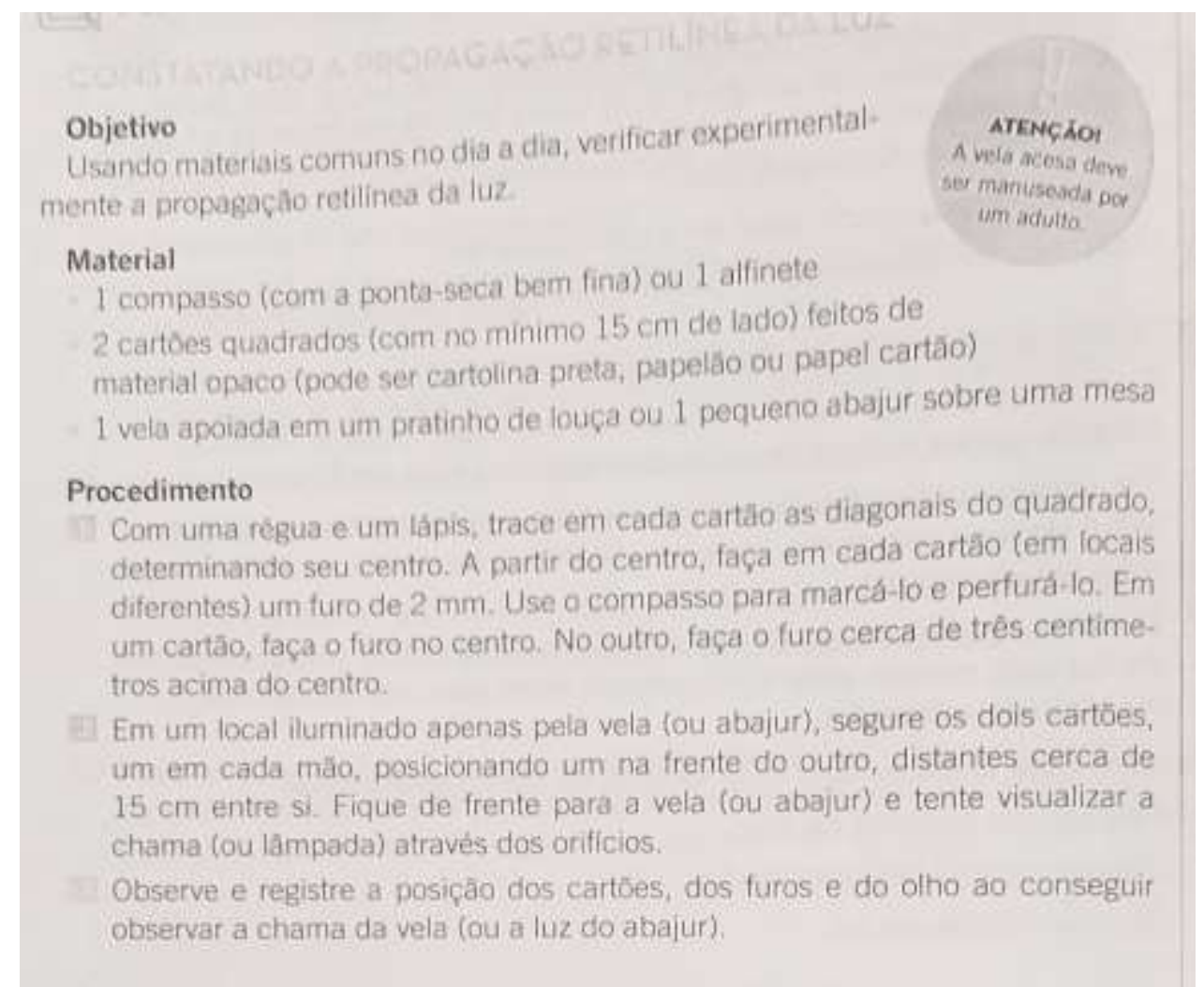

Fonte: Companhia das Ciências (2015, p. 232).

Os cinco LD escolhidos para a análise contemplam a interdisciplinaridade e a contextualização nas AE e nos exercícios. Os exercícios de espelhamento muitas vezes são repetidos em mais de um LD, como a escrita invertida da palavra ambulância e outras questões que utilizam espelhos. Issac Newton, Robert Boyle, René Descartes, Walter Charleton e Robert Hooke são alguns dos principais estudiosos da Óptica; no entanto, averiguou-se que em nenhum exercício foi retratada a história da Ciência, explorando datas, nomes e o contexto em que ocorreu a produção científica, conforme a BNCC orienta. Ribeiro e Silva (2017) afirmam que a história da Ciência para o EC tem a finalidade de introduzir o aluno nas tradições de sua cultura e que, por meio da história, o aluno pode compreender qual o objetivo real do que ele está aprendendo.

Ao considerar as competências gerais da Educação Básica, em conformidade com a área de CN, deve-se garantir aos alunos o desenvolvimento de competências específicas, como: incentivar o aluno a tomar decisões; analisar, compreender e explicar fenômenos da natureza; avaliar como as políticas públicas são aplicadas nas questões socioambientais e culturais; dominar práticas e processos de investigação científica; respeitar a diversidade humana; saber construir argumentos e utilizar diferentes linguagens e tecnologias digitais (Brasil, 2017).

Diante disso, o PNE reconhece a importância de uma BNCC "voltada para os brasileiros, empenhando-se na busca de uma aprendizagem de qualidade, no que tange a Educação Básica em todas as etapas e modalidades do EF, focadas nos direitos, objetivos de aprendizagem e desenvolvimento" (Brasil, 2017, p.324). A BNCC apresenta enfoque no desenvolvimento de competências com cunho social e pedagógico, em que o aluno “deve saber" e "saber fazer", na perspectiva de ter valores, conhecimento, atitudes e habilidades para resolver demandas complexas do seu dia a dia, estar apto ao mundo do trabalho e exercer sua cidadania (Brasil, 2017).

Neste cenário, a BNCC tem compromisso com a educação integral, reconhecendo que a Educação Básica leva ao desenvolvimento do indivíduo, rompendo com várias barreiras, desde a cognitiva a afetiva, sendo que a escola assume um espaço de aprendizagem, de democracia e de inclusão (Brasil, 2017). 


\section{Considerações Finais}

A partir da análise da abordagem interdisciplinar e contextualizada nas AE e nos exercícios de LD de nono ano do EF na área de Ciências Naturais, identificamos que ambos os aspectos estão presentes nos LD selecionados nesta pesquisa. Em relação à habilidade definida, todas as AE estão de acordo com as diretrizes da BNCC, uma vez que, a experimentação precisa evidenciar todas as cores de luz, a partir das três cores primárias e que a cor de um objeto deve estar relacionada com a cor da luz que o ilumina.

Das 123 questões analisadas, 87\% apresentaram interdisciplinaridade e contextualização. Quanto à contextualização, $65 \%$ das questões avaliadas denotam dados numéricos, $25 \%$ retratam o espaço, $16 \%$ datas e épocas (temporal) e $4 \%$ a contextualização (social/cultural). A combinação "numérica e espacial" foi a que mais se destacou nas questões que associam mais de um tipo de contextualização. Além disso, apenas um (1) LD incentivou atividades por meio de projetos (realizar uma intervenção com a comunidade local e escolar), assim como, $80 \%$ das atividades totais incentivaram a produção de trabalhos em grupos.

Foram utilizados na maioria das questões não verbais, textos com figuras. Mapas conceituais, esquemas e outros tipos de metodologias de aprendizagem não foram utilizadas nas AE e exercícios, porém em dois LD os mapas conceituais aparecem ao final do capítulo como forma de resumir os principais conteúdos e conceitos abordados. A interdisciplinaridade uniu mais de uma disciplina nas atividades e exercícios nos LD, mas é incontestável que se necessita averiguar a compreensão do aluno perante as questões que a engloba, principalmente a forma como o professor a aborda. Na maioria das vezes, são professores de Biologia que ministram as aulas de Ciências Naturais do nono ano do EF. Diante disso, indagamos: este professor está apto para abordar conteúdos de Física, Química e Matemática?

Em face das evidências, é de suma importância a atuação do professor frente a todos os aspectos da ação e do processo pedagógico. Investir em cursos de formação complementar os auxiliam a atingir os objetivos almejados, diante de áreas distintas que precisam articular. É preciso integrar as diversas informações contidas nos LD, bem como os conhecimentos prévios dos alunos para promover uma aprendizagem significante. Sem a intervenção do professor na aplicabilidade das AE e dos exercícios, desde a abordagem, a apresentação e a explicação de como executá-los de maneira eficiente, a fim de mostrar ao aluno por meio deste os verdadeiros conceitos e transformar uma informação em conhecimento, o LD perante o exposto, é apenas uma ferramenta de auxílio do professor na condução da ação pedagógica.

A interdisciplinaridade e contextualização são aspectos notórios no EC, que todavia, ainda se constituem um desafio em sala de aula. É necessário ampliar o conceito da interdisciplinaridade para áreas distintas, visto que, na análise desta pesquisa, nenhum exercício dos LD retratou a História da Ciência, explorando datas, nomes e o contexto em que ocorre a produção científica. Consideramos que este estudo é passível de novas discussões e pesquisas para outros níveis e modalidades de ensino, uma vez que, a interdisciplinaridade e a contextualização abrem uma variedade de possibilidades no EC.

\section{Referências}

Anadrade, K. A. (2016). As concepções de linguagem nos livros didáticos de língua portuguesa. Revista do Curso de Letras da UNIABEU. 7(2).

Aragão. S. B. C. (2019). A alfabetização científica na formação inicial de professores de ciências: análise de uma unidade curricular planejada nessa perspectiva. 2019. 236f. Tese (Doutorado) - Programa Interunidades em Ensino de Ciências, Faculdade de Educação, Instituto de Física, Instituto de Química e Instituto de Biociências, Universidade de São Paulo, São Paulo.

Aragão, S. B. C. (2014). Alfabetização científica: concepções dos futuros professores de química. 2014. Dissertação (Mestrado) - Faculdade de Educação, Instituto de Física, Instituto de Química e Instituto de Biociências, Universidade de São Paulo, São Paulo.

Brasil. (2017). Base Nacional Comum Curricular.http://basenacionalcomum.mec.gov.br/images/BNCC_EI_EF_110518_versaofinal_site.pdf

Brasil. (2010). Ministério da Educação. Conselho Nacional de Educação. http://portal.mec.gov.br/index.php?option=com_doc man\&view=d ownload\&ali as=6324-pceb011-10\&category_slug=agosto-2010-pdf\&Itemid=30192 
Brasil. (2018). Escolha do Livro Didático. MEC. http://portal.mec.gov.br/pnld/indexphpoptioncomcontentaviewarticleaidindexphpoptioncomcontentaview articleaid 13658

Brasil. (2019). Temas Contemporâneos Transversais na BNCC. Contextos históricos e pressupostos pedagógicos. http://basenacionalcomum.mec.gov.br/imag es/implementacao/contextualizacao_temas_contemporaneos.pdf

Brasil. (2017). Fundo Nacional de Desenvolvimento da Educação - MEC. História do Livro Didático. http://www.fnde.gov.br/component/

Brasil. (2013). Diretrizes Curriculares Nacionais Gerais da Educação Básica. Ministério da Educação. Secretaria de Educação Básica. Diretoria de Currículos e Educação Integral. MEC, SEB, DICEI, 562p.

Brasil. (1996). Lei de Diretrizes e Bases. Ministério da Educação. Lei 9394/96 | Lei $n^{\circ}$ 9.394, de 20 de dezembro de 1996. https://presrepublica.jusbrasil.c om.br/legislacao/109224/lei-de-diretrizes-e-bases-lei-9394-96

Brasil. (2017). Lei de Diretrizes e Bases. Ministério da Educação. Lei no 9.394/1996 - Lei no $4.024 / 1961$ Edição atualizada de 2017. https://www2.senado.leg.br/bdsf/bitstream/handle/id/529732/lei_de_diretrizes_e_bases_1ed.pdf

Borges, T. S., \& Alencar, G. (2014). Metodologias ativas na promoção da formação crítica do estudante: o uso das metodologias ativas como recurso didático na formação crítica do estudante do ensino superior. Cairu em Revista. Ano.3, n.4.

Camillo, C. M., \& Muller, L. (2020). A produção de história em quadrinhos na Educação do Campo: análise sobre as tecnologias digitais na aprendizagem. Temática, 16(4). https://doi.org/10.22478/ufpb.1807-8931.2020v16n4.51576

Camillo, C. M. (2021). Neurociência e a aprendizagem no ensino Ciências. Research, Society and Development, 10(6). http://dx.doi.org/10.33448/rsdv10i6.15721

Cardoso, F. S., Motta, E. S., Castro, H. C. \& SÁ, S. R. A. N. (2017). A complexidade e a interdisciplinaridade: breves reflexões nos contextos histórico e atual do ensino. Revista Práxis, 9(18), 33-41.

Chassot, A. (2011). Alfabetização científica: questões e desafios para a educação. (5a ed.), Unijuí, p.368.

Catelan, S. S., \& Rinaldi, C. (2018). A atividade experimental e o ensino de ciências: contribuições. Experiências em Ensino de Ciências. 13(1).

Cursino, A. G. (2017). Contribuições das tecnologias para uma aprendizagem significativa e o desenvolvimento de projetos. Dissertação (Mestrado em Projetos Educacionais em Ciência). Universidade de São Paulo, SP.

Lago, W. L. A., Araújo, J. M. \& Silva, L. B. (2015). Interdisciplinaridade e Ensino de Ciências: perspectivas e aspirações atuais do ensino. Saberes, 1(11), 5263.

Matos, J. (2012). A história nos livros didáticos: o papel das políticas governamentais na produção de veiculação do saber histórico. Historiae, 3(1).

Minayo, M. C. S. (2010). O desafio do conhecimento: Pesquisa Qualitativa em Saúde. (12a ed.). Hucitec-Abrasco.

Morin, E., \& Diaz, C. (2016). Reinventar a educação: abrir caminhos para a metamorfose da humanidade. Palas Athena.

Nicoletti, E. R., \& Sepel, L. M. N. (2017). Contextualização e Interdisciplinaridade nas provas do ENEM: analisando as questões sobre vírus. Acta Scientiae, 18(1), 204-220.

Novak, J. D. (1981). Uma Teoria de educação. Pioneira.

Oliveira, J. I. (2018). Projetos Escolares para Melhoria das Práticas Pedagógicas. Dissertação (Mestrado). Programa de Pós-graduação em Docência e Gestão da Educação: Administração Escolar e Administração Educacional. Universidade Fernando Pessoa.

Pozo, J. I., \& Crespo, M. A. G. (2009). A aprendizagem e o ensino de ciências: do conhecimento cotidiano ao conhecimento científico. (5a ed.), Artmed, 296 p.

Ribeiro, G., \& Silva, J. L. (2017). A relevância da história da Ciência para o Ensino de Ciência: elementos introdutórios. Revista Acadêmica GUETO, 9(1), 20

Roberts, D. A. (2007). Scientifc literacy/science literacy. In: Abell, S. K., \& Lederman, N. G. (Ed.). (2007). Handbook of research on science education (p. 729-782). Londres: Lawrence Erbaum Associates.

Rodrigues, L., \& Vestena, R. (2013). O livro didático e a alfabetização científica em ciências: uma análise nos anos iniciais do ensino fundamental da modalidade de educação de jovens e adultos. Disciplinarum Scientia. Série: Ciências Humanas, 14(1), 47-64.

Romano, E. P. (2020). Lição de casa - que prática é essa? 2008. http://www.ecc.br/site/pasta_258_0_licao-de-casa-\%C3\%82\%E2\%80\%93-que-pratica-eesta-.html

Santos, W. L. P., \& Mortimer, E. F. (1999). Concepções de professores sobre contextualização social do ensino de química e ciências. In: 54 Reunião Anual da Sociedade Brasileira de Química, 22, 1999. Anais Poços de Caldas: Sociedade Brasileira de Química.

Santos, W. L. P. (2007). Contextualização no Ensino de Ciências por Meio de Temas Cts em uma Perspectiva Crítica. Ciência \& Ensino, 1

Santos, E. S. S. (2020). Trabalhando com Alunos: Subsídios e Sugestões. Revista Gestão Universitária, Edição 40. http://www.udemo.org.br/RevistaPP_02 _05Professor.htm 